\title{
Unmet need in the hyperlipidaemia population with high risk of cardiovascular disease: a targeted literature review of observational studies
}

\author{
S. Mitchell ${ }^{1 *}$, S. Roso ${ }^{2}$, M. Samuel ${ }^{3}$ and M. Pladevall-Vila ${ }^{4,5}$
}

\begin{abstract}
Background: The aim of this study was to examine recommended target levels of low-density lipoprotein cholesterol $(L D L-C)$ for hyperlipidaemia patients at high risk (i.e., with two or more risk factors or coronary heart disease or its risk equivalents) for cardiovascular disease (CVD); to determine LDL-C targets recommended by guidelines, and to examine the proportions of patients who do not achieve targeted LDL-C levels in real-world studies.

Methods: Electronic databases were searched: Medline, Medline In-Process, Embase, BIOSIS, and the Cochrane Library (1 January 2005 to 31 December 2013). Guideline searches were limited to publications in the last 5 years. There were no geographical or language restrictions.

Results: Seventeen guidelines and 42 observational studies that reported on high-risk hyperlipidaemia patients were identified. The National Cholesterol Education Program-Adult Treatment Panel III's LDL-C target levels were the most common guidelines used for patients with very high hyperlipidaemia. However, between 68 and $96 \%$ of patients in the studies did not achieve an LDL-C goal $<70 \mathrm{mg} / \mathrm{dL}$, except in one study conducted in China (16.9\%). In high-risk patients, 61.8 to $93.8 \%$ did not achieve a target of $<100 \mathrm{mg} / \mathrm{dL}$. Regarding common comorbidities, patients with concomitant CVD or diabetes were least likely to reach their target LDL-C goals.

Conclusion: In patients with high risk for CVD, the majority of patients do not attain recommended LDL-C goals, highlighting worldwide suboptimal hyperlipidaemia management and missed opportunities for reduction of the patients CVD risk. Lipid-modifying management strategies need to be intensified.
\end{abstract}

Keywords: Hyperlipidaemia, LDL-C, Cardiovascular, Mortality, Review, Observational studies

\section{Background}

Hyperlipidaemia is an increase in serum levels of one or more of the following: low-density lipoprotein cholesterol (LDL-C), total cholesterol, triglycerides, or both total cholesterol and triglycerides (combined hyperlipidaemia). Patients with hyperlipidaemia are mostly asymptomatic; however, these patients have an increased risk for cardiovascular disease (CVD), which is the main cause of premature death, and has been a major cause of disability and ill health in recent years [1-4].

\footnotetext{
* Correspondence: semitchell@rti.org

${ }^{1}$ RTI Health Solutions, The Pavilion, Towers Business Park, Wilmslow Road,

Didsbury, Manchester M20 2LS, UK

Full list of author information is available at the end of the article
}

Lipid-lowering medications include statins, fibrates, and anion-exchange resins; they are recommended as part of the management strategy for primary or secondary prevention of CVD in adults with a $20 \%$ or greater 10 -year risk of developing CVD [5]. In large, randomised, controlled trials, statins in particular have been shown to be effective in preventing coronary heart disease events and in reducing overall mortality $[4,6-8]$. Statins therefore are recommended as first-line therapy, whereas fibrates and anion-exchange resins are considered second-line therapy, or combination therapy when used with statins [9]. Guidelines published for Europe [4] and other countries before $2013[10,11]$ recommend a treat-to-goal paradigm for LDL-C levels. However, despite clear evidence that there 
is a positive association between LDL-C levels and the risk of cardiovascular (CV) events, there is inconclusive evidence that achieving specific goal levels reduces the risk of $\mathrm{CV}$ events.

A number of published studies have reported that patients do not achieve LDL-C goals in the hyperlipidaemia population [12, 13]; however, to our knowledge the latest evidence has not been collated in a rigorous manner. The current study performed a targeted review of the published guidelines to identify the recommended treatment targets for LDL-C levels in clinical practice. This review also assembled the best evidence from recently published observational studies to determine the proportions of very high-risk, high-risk, and moderately high-risk patients who do not achieve targeted LDL-C levels in a real-world setting-that is, in routine clinical practice-and, if reported in studies, the reasons for not achieving target levels. This review provides a qualitative overview of the available data; a meta-analysis was not performed and a statistical analysis of the results was not undertaken.

\section{Methods}

\section{Literature search and data extraction}

This review was performed in an unbiased manner by using a prespecified protocol and an explicit, reproducible plan for the literature search and synthesis. A targeted literature search to identify observational studies was performed in the following databases: Medline, Medline In-Process, Embase, BIOSIS, and the Cochrane Library (from 1 January 2005 to 31 December 2013). Guideline searches of these databases were limited to publications in the last 5 years in order to evaluate the most recent practice patterns and recommendations. Hand searches also were performed, including a search of the Agency for Health Care Research and Quality's National Guideline Clearing House. Systematic reviews were used to identify primary studies but were not included in this review. No limitations on publication language or geographic perspective were applied. Articles that were published in a non-English language were translated as required.

Search terms to identify guidelines and other primary studies included combinations of free text and Medical Subjects Headings (MeSH) and consisted of the following sets of terms:

- Health condition of interest (e.g.,

"Hypercholesterolemia"[Majr],

hypercholesterol"[Title], Hyperlipidemias[Majr],

hyperlipidemia[Title], hyperlipidemias[Title],

hyperlipidaemia[Title], hyperlipidaemias[Title])

- Suboptimal response (e.g., sub-optim*[Title/Abstract], suboptim*[Title/Abstract], sub optim*[Title/Abstract],
"goal"[Title/Abstract], "target"[Title/Abstract], optimum[Title/Abstract], achieve"[Title/Abstract])

- Outcomes of interest (e.g., LDL-C goal)

- Guidelines and clinical studies ("Practice Guidelines as Topic"[MeSH], "Guidelines as Topic"[MeSH], "Practice Guideline"[Publication Type], "Prospective Studies"[MeSH], "Registries"[MeSH], observational stud"[Text Word], "Retrospective Studies"[Majr]).

The full Medline literature search strategy is presented in Additional file 1: Table S1; this search strategy was adapted for other databases.

Screenings of titles, abstracts, and full-text articles for eligibility were performed by one researcher; a second researcher performed a quality check of a random selection of $10 \%$ of all references identified from the searches; any disagreement was resolved by consensus, with input from an experienced senior researcher. The following were the predefined inclusion criteria:

Population: Adult patients with hyperlipidaemia with moderately high risk, high risk, or very high risk of CVD

Intervention: No limits applied

Outcomes: Target LDL-C levels recommended by guidelines; the proportion of patients who did not achieve the LDL-C targets; and the reasons, if reported in the study, for not achieving the target LDL-C levels Study type: Observational studies; clinical practice guidelines

Exclusions: Studies with a sample size of less than 100 subjects or studies in familial hypercholesterolaemia

\section{Data synthesis}

The treatment guidelines obtained from various countries were used to examine differences among recommended LDL-C target levels for patients with hyperlipidaemia. Results of the observational studies generally were summarised quantitatively, using descriptive statistics; due to the heterogeneity between the included studies a statistical analysis was not undertaken.

To qualitatively synthesise data from the observational studies, we summarised data in detailed evidence tables and figures. The summarised data included information on the study design; population size; patient characteristics, including risk category definitions (very high risk, high risk, and moderately high risk of CVD); and results (i.e., the LDL-C target level recommended for hyperlipidaemic patients who are at very high risk, high risk, and moderately high risk of CVD; the proportion of patients who do not achieve the LDL-C target levels; and the reasons for not achieving these targets). The definition of high risk was extracted as reported by the study; generally high risk was defined as two or more risk factors for 
coronary heart disease (CHD) or its risk equivalents. A quality assessment of the included studies was not performed because this review did not evaluate comparative effectiveness and safety of treatments used in the management of hyperlipidaemia; rather, we evaluated, within the studies reviewed, the general trends in patients not achieving LDL-C target goals.

\section{Results}

\section{Study identification and characteristics}

Searches for guidelines identified 545 records (databases = 533; Internet and hand searches $=12$ ). After the initial screening of titles and abstracts (level 1 screening), 82 publications (databases searches $=70$; Internet and hand searches $=12$ ) were selected for full-text (level 2) screening.
Ultimately, 17 publications, describing treatment guidelines from more than 20 countries, were included in the current review. Searches for clinical studies retrieved 1620 records (databases $=1620$; Internet and hand searches $=0$ ) and 42 observational studies that reported data for highrisk patients (that is, patients with very high risk, high risk, and moderately high risk of CVD) were included. The volume of studies included and excluded at each stage of screening is shown in the Preferred Reporting Items for Systematic Reviews and Meta-Analyses flow chart [14] presented in Fig. 1.

\section{Treatment guidelines}

The European Society of Cardiology and the European Atherosclerosis Society (ESC/EAS) guidelines for LDL-C

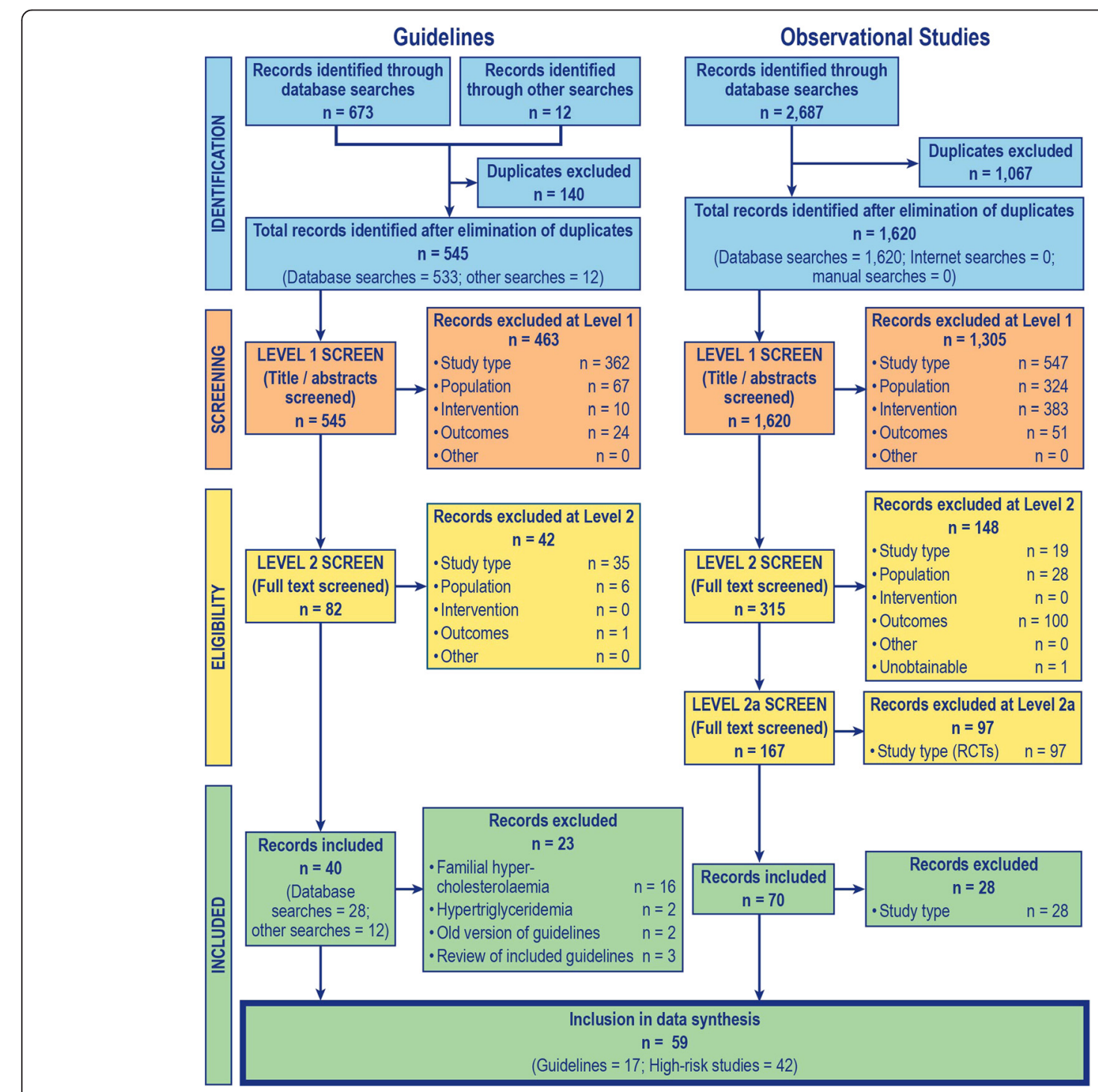

Fig. 1 Flow Chart for Study Inclusion and Exclusion. PRISMA preferred reporting items for systematic reviews and meta-analyses, RCT randomised, controlled trial 
target levels for patients with hyperlipidaemia are widely used in European clinical practice in Austria, Belgium, Denmark (endorsed by the Danish Society of Cardiology), France, Ireland, Italy (Nota 13, the prescribing guideline for hyperlipidaemia, references the ESC/EAS), Poland (recommended by Polish Cardiology Association), and Russia. Additionally in Austria, there is a consensus document, Lipidkonsensus, prepared by experts from eight Austrian medical associations $[15,16]$. In Finland, the Netherlands, Norway, Spain, Sweden, Switzerland, the United Kingdom, and South Africa, experts have developed, or are planning to develop, country-specific guidelines; the recommended LDL-C target levels for various risk categories in these guidelines varied slightly compared with the levels recommended in ESC/EAS guidelines (Additional file 1: Table S2). The new guidelines from the American College of Cardiology and the American Heart Association (ACC/AHA) developed in conjunction with the National Heart, Lung, and Blood Institute do not recommend a target LDL-C level for treated patients because, according to the authors, there is a lack of evidence from clinical trials. Rather, the ACC/AHA guidelines recommend intensive treatment options based on risk assessment and LDL-C levels to reduce CVD events. In Asia, most countries currently follow the National Cholesterol Education Program-Adult Treatment Panel III (NCEP-ATP-III) guidelines.

\section{Recommended LDL-C target levels for patients with varying underlying risks}

Recommended LDL-C target levels for very high-risk or high-risk patients This review observed that the risk definitions were not consistently used between guidelines. Eleven guidelines recommended target LDL-C levels for patients with a high or very high risk for $\mathrm{CV}$ disease (Additional file 1: Table S2). For patients with CHD, or who have two or more CVD risk factors, CHD risk-equivalent conditions, or diabetes, the recommended LDL-C target levels ranged from $<70 \mathrm{mg} / \mathrm{dL}(<1.8 \mathrm{mmol} / \mathrm{L})$ to $<120 \mathrm{mg} /$ $\mathrm{dL}(3.1 \mathrm{mmol} / \mathrm{L})$; the majority of the guidelines recommended a target of $<100 \mathrm{mg} / \mathrm{dL}(<2.6 \mathrm{mmol} / \mathrm{L})$ [11, 15-21]. Two guidelines from Europe $[5,20]$ recommended a target LDL-C level $<70 \mathrm{mg} / \mathrm{dL}(<1.8 \mathrm{mmol} / \mathrm{L})$ for very high-risk patients; the ACC/AHA guidelines [1] recommended treatment with a moderate- or high-intensity statin (depending on the patient's 10-year atherosclerotic CVD risk) in patients with a LDL-C level of between 70 and $189 \mathrm{mg} / \mathrm{dL}$ $(1.8-4.9 \mathrm{mmol} / \mathrm{L})$.

Patients with known CVD are at very high risk for CV events. Long-term treatment to prevent recurrent cardiac morbidity and mortality and to improve quality of life in patients who had a prior episode of myocardial infarction, acute coronary syndrome, angina, stroke, peripheral artery disease, or peripheral vascular disease, or who are at high risk of ischaemic cardiac events for other reasons, such as severe coronary artery stenoses or prior coronary surgical procedures [22], is discussed as secondary prevention. Thirteen treatment guidelines recommended specific LDL-C targets for secondary prevention. The most common target was $<100 \mathrm{mg} / \mathrm{dL}$ $(<2.6 \mathrm{mmol} / \mathrm{L})$, which was recommended by eight different guidelines in Asia [17]. For very high-risk patients, Philippines and Thailand recommend a lower target level of less than $70 \mathrm{mg} / \mathrm{dL}(1.8 \mathrm{mmol} / \mathrm{L})$. In the United Kingdom, the guidelines published by the National Collaborating Centre for Primary Care and Royal College of General Practitioners [5] set a target LDL-C level of $\leq 77 \mathrm{mg} / \mathrm{dL}(\leq 2.0 \mathrm{mmol} / \mathrm{L})$ for adults with clinical evidence of CVD. A broader target of between 66 and $97 \mathrm{mg} / \mathrm{dL}(1.7$ and $2.5 \mathrm{mmol} / \mathrm{L})$ is recommended by the Norwegian Directorate of Health, for persons with atherosclerosis or CVD.

Recommended LDL-C target levels for moderately high-risk patients Eleven guidelines recommended target LDL-C levels for moderately high-risk patients (those with no CHD but with $\geq 2$ risk factors) (Additional file 1: Table S2). The recommended targets ranged from $77 \mathrm{mg} / \mathrm{dL}(\leq 2.0 \mathrm{mmol} / \mathrm{L})$ in the Canadian Cardiovascular Society guidelines [23] to $<140 \mathrm{mg} / \mathrm{dL}(3.6 \mathrm{mmol} / \mathrm{L})$ in the Japanese Atherosclerosis Society guidelines [11]. Most guidelines recommended a target of $<130 \mathrm{mg} / \mathrm{dL}$ (3.4 mmol/L) [15-19, 24].

\section{Proportion of high- or very high-risk patients not achieving LDL-C targets}

Numerous clinical and epidemiologic studies have shown that an elevated LDL-C level is one of the major modifiable risk factors associated with the development of CHD. Of the observational studies that were included in the current review, NCEP-ATP-III LDL-C targets were most commonly used, followed by the Canadian Working Group, and the Third Joint European Task Force of the European Society of Cardiology; other studies used country-specific guidelines. In very high-risk patients, between 68 and $96 \%$ did not achieve an LDL-C goal of $<70 \mathrm{mg} / \mathrm{dL}$, as recommended by the NCEP-ATPIII guidelines (Fig. 2), with the exception of one study conducted in China (16.9\%). Most studies found that most high-risk patients (61.8-93.8 \%) did not achieve a target of $<100 \mathrm{mg} / \mathrm{dL}$ as recommended by the NCEPATP-III guidelines (Fig. 3); nine studies reported lower proportions (0.0-47.3\%). For moderately high-risk patients (Fig. 4) in 10 out of 14 studies, 35.6 to $78.2 \%$ did not achieve the NCEP-ATP-III target goal of $<130 \mathrm{mg} / \mathrm{dL}$. Further, four studies conducted in the United States reported lower proportions, between 6.6 


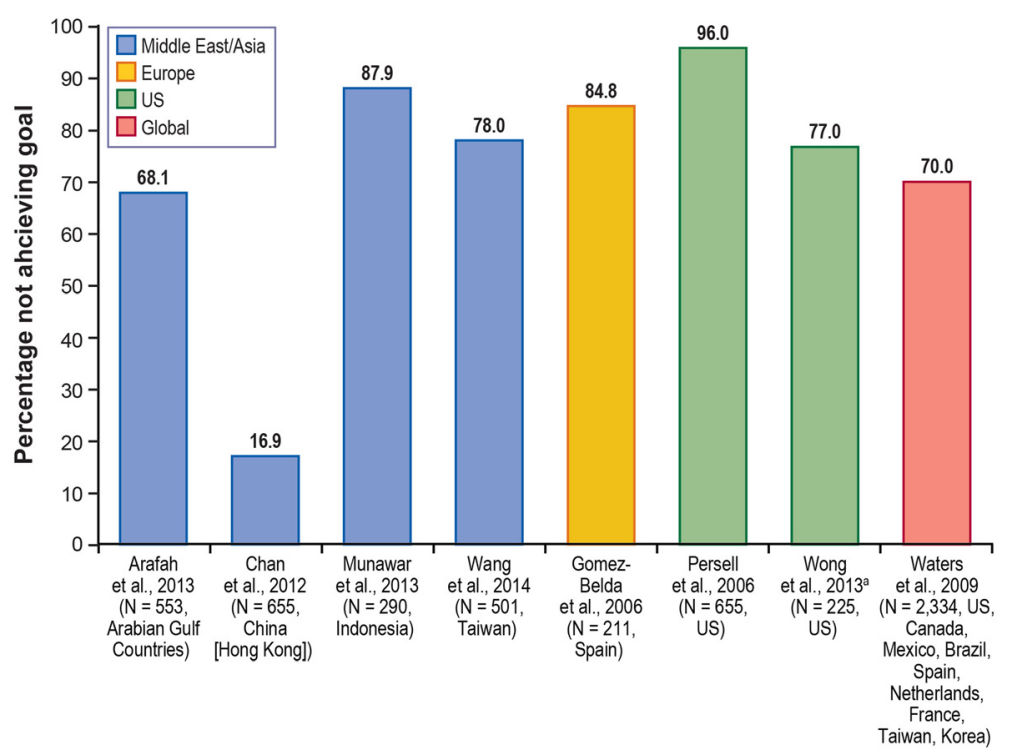

Fig. 2 Patients (Very High Risk) Not Achieving NCEP-ATP-III Guidelines LDL-C Level Target, <70 mg/dL (1.81 mmol/L). LDL-C low-density lipoprotein cholesterol, NCEP-ATP-III National Cholesterol Education Program-Adult Treatment Panel III, US United States. Notes: Treated and untreated patients. The N represents patients at high risk, a subset of the total number of patients studied. Sources: [29, 35-37, 39, 43-45]

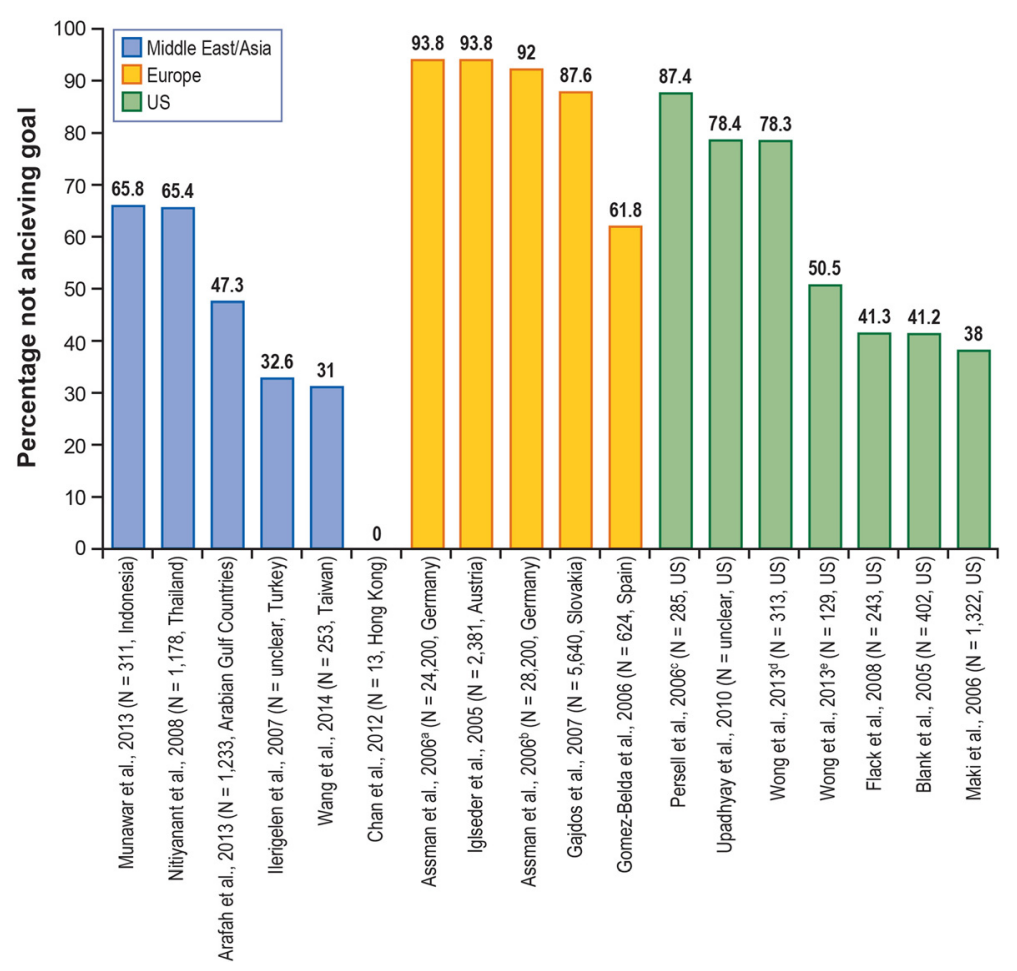

Fig. 3 Patients (High Risk) Not Achieving NCEP-ATP-III Guidelines LDL-C Level Target, < 100 mg/dL (2.56 mmol/L). LDL-C low-density lipoprotein cholesterol, NCEP-ATP-III National Cholesterol Education Program-Adult Treatment Panel III, US United States. ${ }^{\text {a }}$ Primary prevention, 9 months, women. ${ }^{b}$ Primary prevention, 9 months, men. ${ }^{c}$ Based on 2004 guidelines. ${ }^{d}$ Treated and untreated patients. ${ }^{e}$ Treated patients. Sources: [25, 26, $29,34-36,39,43-51]$ 


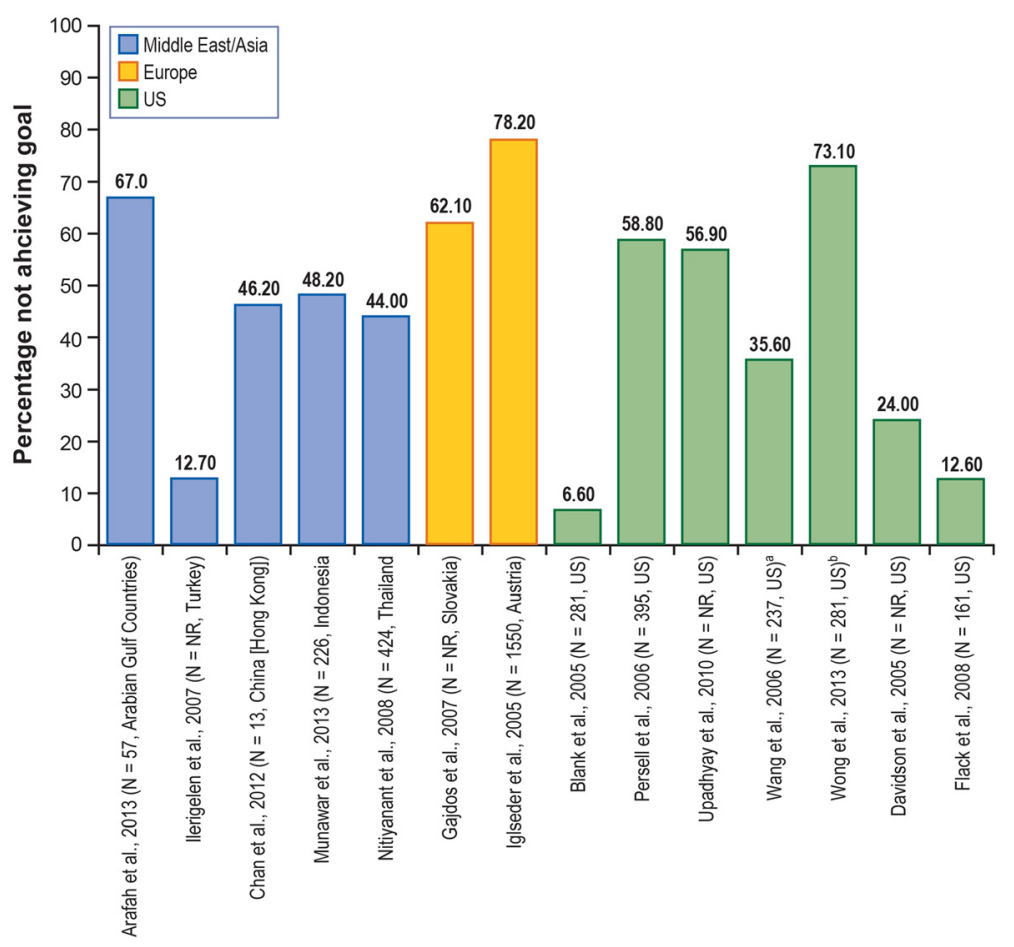

Fig. 4 Patients (Moderately High Risk) Not Achieving NCEP-ATP-III Guidelines LDL-C Level Target, < $130 \mathrm{mg} / \mathrm{dL}$ (3.0 mmol/L). LDL-C low-density lipoprotein cholesterol, NCEP-ATP-III National Cholesterol Education Program-Adult Treatment Panel III, NR not reported, US United States. Note: The $\mathrm{N}$ represents patients at high risk, a subset of the total number of patients studied. ${ }^{a}$ Based on data from 2003. ${ }^{\mathrm{b}}$ Treated and untreated patients. Sources: $[25,29,35,36,44-53]$

and $24.0 \%$. Similar results were observed in Ilerigelen et al. [25] (12.7\%) which was conducted in Turkey.

Three studies that followed the Canadian Working Group guidelines, using a target of $<97 \mathrm{mg} / \mathrm{dL}$ $(2.5 \mathrm{mmol} / \mathrm{L})$, reported that between 38.0 and $42.3 \%$ of high-risk patients did not achieve this goal [26-28]. A further five studies also used a target of $<97 \mathrm{mg} / \mathrm{dL}$ $(<2.5 \mathrm{mmol} / \mathrm{L})$, as recommended by the Third Joint European Task Force guidelines, the European Society of Cardiology, and guidelines from Brazil and Hungary; 41.7 to $89.7 \%$ patients did not achieve this goal [29-33].

\section{Proportion of high- or very high-risk patients with con- comitant conditions not achieving LDL-C targets}

Overall, of all of the common comorbidities, patients with concomitant CVD and diabetes seemed the least likely to reach their target LDL-C goals (Additional file 1: Table S3).

Concomitant health conditions may have an impact on hyperlipidaemia patients' CV risk category and, by extension, their LDL-C target. This is particularly true for CHD and other conditions that are classed as CHD risk equivalents because these are considered to be the highest risk indicators for CVD, and therefore have the most stringent LDL-C targets. The studies we reviewed showed considerable variability in LDL-C goal achievement for patients with different concomitant conditions (Additional file 1: Table S3). In the majority of the studies, more than $60 \%$ of patients failed to achieve the LDL-C target levels. In a $4 \mathrm{E}$ Registry study [34], the percentage of male patients with diabetes mellitus failing to achieve goal levels was similar to the percentage of male patients without diabetes failing to achieve goal levels (74.7 \% vs. $71.7 \%$ ). Women without diabetes mellitus, however, did much better in achieving their individual lipid goals: $55 \%$ did not attain the goal levels, compared with $76 \%$ of women with diabetes. However, achievement of treatment goals in patients with diabetes was just as poor as in other high-risk groups in the $4 \mathrm{E}$ cohort. In a cross-sectional survey conducted in Asia [35], $>70 \%$ of patients with diabetes, CHD, carotid artery disease, peripheral arterial disease, metabolic syndrome, or other multiple risk factors (10-year CHD risk $>20 \%$ ) did not achieve the recommended LDL-C targets.

Some studies observed that the number of patients with CHD who do not achieve their LDL-C targets was not as high ( $<50 \%)$; but most studies reported that the majority of patients did not meet their targets. A similar trend was observed in patients with other concomitant conditions such as hypertension, stroke, and kidney disease. One common theme among the studies that compared concomitant conditions was that patients with multiple conditions (i.e., 
patients at higher CV risk) were less likely to reach LDL-C goals than patients with a single condition. Another notable theme was that, within an individual study, patients in higher CV risk categories were less likely to reach LDL-C target goals than patients in lower $\mathrm{CV}$ risk categories. However, it should be noted that patients in higher risk categories have lower target goal levels.

\section{Potential reasons for patients not achieving target $L D L-C$ levels}

The reasons why patients did not achieve their LDL-C targets was not consistently investigated nor reported across the studies included in this review. Of the studies that did report reasons, only a few conducted univariate or multivariate analysis to investigate the relationship between patient-level factors that may have contributed to failure to reach targets. Patient characteristics such as gender; age; race; body mass index; and comorbid conditions such as diabetes, CHD, peripheral arterial disease, and carotid arterial disease are some of the known risk factors that influence the achievement of LDL-C target goals. However, it is difficult to reach any firm conclusions because some of the studies report conflicting evidence.

Two studies, one of which was a large international survey, reported that males were more likely to attain their LDL-C target goals than females [36, 37], with a univariate analysis finding that being female decreased the odds of attaining the LDL-C goal (odds ratio $=0.62$, $95 \%$ CI, 0.390.99; $P=0.043$ ) [36]. Contrary to these findings, two large studies reported that successful LDL-C goal attainment was positively associated with being female [29, 38].

A Chinese study found that older age increased the odds (odds ratio $=1.02 ; 95 \% \mathrm{CI}, 1.00-1.05$ for every 10 years increment in age; $P=0.038$ ) of attaining the LDL-C target goals [36]. Older age was also found to be a multivariate predictor of successful LDL-C goal achievement in a worldwide multicenter study [37]. Conversely, a large study in the US found that older age was negatively associated with LDL-C control [38]. Similarly, another study reported that LDL-C goal attainment was significantly related to an age $<40$ years [29].

As might be expected, several studies reported that baseline total cholesterol or LDL-C levels had an inverse relationship with LDL-C target achievement, i.e., higher baseline total cholesterol or LDL-C was associated with significantly lower odds of attaining LDL-C goals, $P<0.001[35,36,39]$. Baseline $C V$ risk was also found to influence attainment of LDL-C goals. Two studies conducted in Asia [35, 39] suggested that goal attainment was inversely related to baseline $\mathrm{CV}$ risk, i.e., the higher the $\mathrm{CV}$ risk at baseline, the less likely the patients were to reach their target. These findings were supported by a large multicentre, international trial, which found that being in a lower risk CV group was a multivariate predictor of successful LDL-C goal achievement [37].

Patient adherence has been considered to be a major factor in the low rate of LDL-C target attainment; higher adherence to treatment is linked to higher proportions of patients reaching their targets [35]. Reasons for nonadherence were cited as patients forgetting to take their medication or stopping taking their medication when their cholesterol had returned to normal [33, 35, 40]. A crosssectional study in Brazil suggested that non-adherence was common in the population with scarce financial resources due to the high cost of medication [30]. Improper communication between health care professionals and the patients, which was particularly clear among aged patients or those with poor literacy, was also found to be an important factor for non-adherence [30].

Whilst current guidelines for treating hyperlipidaemia provide specific algorithms for the treatment of chronic conditions, they also present a more complex approach to lipid management, which requires physicians to make decisions about multiple options for treating each patient. A cross-sectional survey conducted in the United States [41] showed that although a significant minority of patients did not receive a dose increase when one appeared warranted, approximately $70 \%$ of patients did receive a dose increase at some point. There was a highly significant association of several physician attitudes and beliefs with the decision to increase the statin dose; physicians who believed that "statins are effective" were more likely to increase statin dose, whereas those who had an attitude that "close enough to goal is good enough" were less likely to switch or titrate to higher statin dose [41]. Of the patients who received an increase in statin dose, $50 \%$ were still not at goal and few were on the highest doses, suggesting that physicians are not "treating to goal" [41].

\section{Discussion}

In this review, evidence from the observational studies shows that despite the increasing global awareness of the need for the management of CV events, more than half of high-risk patients do not attain the lipid levels recommended by the published guidelines. Although lipidlowering drugs such as statins are proven to have beneficial effects on long-term outcomes, hyperlipidaemia remains unsatisfactorily managed in routine clinical practice. The ESC/EAS and NCEP-ATP-III guidelines are the primary guidelines used in clinical practice around the world; they recommend a treat-to-goal paradigm. In the United States, the ACC/AHA's latest guidelines [1] do not recommend a target LDL-C level; rather, they recommend intensive treatment options based on risk assessment and LDL-C levels. The panel believes that the use of LDL-C targets 
may result in the overtreatment of patients with nonstatin drugs that have not shown to reduce the risk of $\mathrm{CV}$ events [1].

Some studies suggested that achieving LDL-C goals was inversely related to baseline CV risk [35, 37, 39], although one of the reasons put forward for not achieving goals is that the target levels are lower for such patients $(<70 \mathrm{mg} / \mathrm{dL})$. Treatment non-adherence also is cited as a common issue in various studies [27, 30, 33, 35]. It is thought that non-adherence may be due to scarce financial resources [30] or to improper communication between the health care professional and the patient, particularly among elderly patients and those with poor literacy. In addition, poor physician adherence to treatment guidelines could also play a crucial role. Other reasons for poor attainment of treatment goals can include inadequate dosing, failure to properly up titrate the dose, not switching to a more potent drug when necessary, and a lack of follow-up after initiation of treatment. According to a 4E Registry study in Germany, treatment, once started, was rarely modified. The statin dose was increased in only $10 \%$ of patients; leading to the assumption that doctors are not aware of how to reach target values [34]. In observational studies, patients and their physicians select treatment on the basis of clinical need or preference, which can result in differences in clinical outcomes solely because of differences between those who receive and those who do not receive a treatment. These results must be interpreted in consideration of the relatively high rate of missing data at the follow-up visits. It is possible that predominantly 'difficult-to-treat' or nonadherent patients were lost. Good management strategies, appropriate therapeutic approaches, and good patient and physician adherence to recognised practice guidelines will be crucial in achieving favourable outcomes. Patients in a high-risk or a very high-risk category tend to have lower achievement of LDL-C goals, highlighting suboptimal hyperlipidaemia management worldwide or even the setting of unrealistic goals [42]. Patients in higher CV risk categories tend to have more stringent LDL-C target levels, which may contribute to failure to achieve target levels. Limited evidence suggests that the reasons for not achieving target LDL-C goals include gender, age, comorbidities (e.g., diabetes and $\mathrm{CV}$ risk), hypertension, baseline LDL-C and total cholesterol levels, and choice of treatments and dosages. Further primary studies are needed to rigorously explore these reasons.

\section{Conclusion}

The results of the current review suggest there are several unmet needs in treating hyperlipidaemic patients: the reduction of the patients' risks for CVD and the consequent reduction of the occurrence of $\mathrm{CV}$ events have confirmed the necessity of intensifying lipid-modifying management. The failure of large numbers of patients to achieve LDL-C targets, and specifically the failure of patients in high-risk or very high-risk categories, to attain LDL-C goals in a number of countries highlight suboptimal hyperlipidaemia management worldwide.

\section{Additional file}

Additional file 1: Table S1. MEDLINE Literature Search Strategy. Table S2. Recommended LDL-C Targets for High-Risk Patients From Treatment Guidelines. Table S3. Patients With Pre-existing Conditions Not Achieving Target LDL-C Levels. (DOCX 63 kb)

\section{Competing interests}

Sarah Mitchell and Manel Pladevall-Vila are employees of RTI Health Solutions and were paid consultants to Pfizer in connection with the development of this manuscript. Miny Samuel was a paid employee of RTI Health Solutions during the preparation of this manuscript. Stephanie Roso is a paid employee of Pfizer Ltd.

\section{Authors' contributions}

All authors meet criteria for authorship as recommended by the International Committee of Medical Journal Editors and are fully responsible for all content and editorial decisions. The authors were involved at all stages of manuscript development, and all authors read and approved the final manuscript. SM and MS were involved in the study design and were responsible for the acquisition and interpretation of data and the writing of the manuscript. SR played a crucial role in the concept and design of the study, provided review and input at all critical stages of the literature review, was involved with interpretation of data, and was involved in reviewing and revising the content of the manuscript. MP-V provided clinical expertise during the study and was involved in reviewing and designing the literature review, interpreting the evidence, and reviewing and revising the content of the manuscript.

\section{Acknowledgements}

None.

Funding

This study was funded by Pfizer Ltd.

\section{Author details}

${ }^{1}$ RTI Health Solutions, The Pavilion, Towers Business Park, Wilmslow Road, Didsbury, Manchester M20 2LS, UK. ${ }^{2}$ Pfizer Ltd., Walton Oaks, Dorking Road, Walton-on-the-Hill, Tadworth, Surrey KT20 7NS, UK. ${ }^{3}$ NUS Yong Loo Lin School of Medicine, NUHS Tower Block, Level 11, 1E Kent Ridge Road, Singapore 119228, Singapore. ${ }^{4}$ RTI Health Solutions, Trav. Gracia 56 Atico 1 08006, Barcelona, Spain. ${ }^{5}$ The Center for Health Policy and Health Services Research, Henry Ford Health System, Detroit, MI, USA.

Received: 13 October 2015 Accepted: 8 April 2016

Published online: 26 April 2016

\section{References}

1. Stone NJ, Robinson J, Lichtenstein AH, Bairey Merz CN, Lloyd-Jones DM, Blum CB, et al. 2013 ACC/AHA guideline on the treatment of blood cholesterol to reduce atherosclerotic cardiovascular risk in adults: a report of the American College of Cardiology/American Heart Association Task Force on Practice Guidelines. J Am Coll Cardiol. 2014;63(25 Pt B):2889-934.

2. Yusuf S, Reddy S, Ônnuu S, Anand S. Global burden of cardiovascular diseases, Part II: variations in cardiovascular disease by specific ethnic groups and geographic regions and prevention strategies. Circulation. 2001b;104(23):2855-64.

3. Schedlbauer A, Davies P, Fahey T. Interventions to improve adherence to lipid lowering medication. Cochrane Database Syst Rev. 2010;3:CD004371. doi:10.1002/14651858.CD004371.pub3.

4. Perk J, De Backer G, Gohlke H, Graham I, Reiner Z, Verschuren M, European Association for Cardiovascular Prevention and Rehabilitation (EACPR), ESC Committee for Practice, et al. European guidelines on cardiovascular disease prevention in clinical practice (version 2012). The Fifth Joint Task Force of 
the European Society of Cardiology and Other Societies on Cardiovascular Disease Prevention in Clinical Practice (constituted by representatives of nine societies and by invited experts). Eur Heart J. 2012;13(13):1635-701. doi:10.1093/eurheartj/ehs092. Epub 2012 May 3.

5. Cooper A, Nherera L, Calvert N, O'Flynn N, Turnbull N, Robson J, et al. Clinical guidelines and evidence review for lipid modification: cardiovascular risk assessment and the primary and secondary prevention of cardiovascular disease. London: National Collaborating Centre for Primary Care and Royal College of General Practitioners; 2008. p. 1-236 (revised March 2010).

6. Cholesterol Treatment Trialists' (CTT) Collaboration, Mihaylova B, Emberson J, Blackwell L, Keech A, Simes J, et al. The effects of lowering LDL cholesterol with statin therapy in people at low risk of vascular disease: meta-analysis of individual data from 27 randomised trials. Lancet. 2012;380:581-90.

7. Taylor F, Huffman MD, Macedo AF, Moore TH, Burke M, Davey Smith G, et al. Statins for the primary prevention of cardiovascular disease. Cochrane Database Syst Rev. 2013;1:CD004816.

8. Athyros VG, Papageorgiou AA, Mercouris BR, Athyrou W, Symeonidis AN, Basayannis EO, et al. Treatment with atorvastatin to the National Cholesterol Educational Program goal versus 'usual' care in secondary coronary heart disease prevention. The Greek Atorvastatin And Coronaryheart-Disease Evaluation (GREACE) study. Curr Med Res Opin. 2002;18(4):220-8.

9. Scottish Intercollegiate Guidelines Network (SIGN). Risk estimation and the prevention of cardiovascular disease. A national clinical guideline. 2007. Available at: http://www.sign.ac.uk/pdf/sign97.pdf. Accessed 1 November 2009.

10. Hata Y, Mabuchi H, Saito Y, Itakura H, Egusa G, Ito H, Working Committee on JAS Guideline for Diagnosis and Treatment of Hyperlipidemias, et al. Report of the Japan Atherosclerosis Society (JAS) Guideline for Diagnosis and Treatment of Hyperlipidemia in Japanese adults. J Atheroscler Thromb. 2002;9(1):1-27.

11. Teramoto T, Sasaki J, Ishibashi S, Birou S, Daida H, Dohi S, Japan Atherosclerosis Society, et al. Executive summary of the Japan Atherosclerosis Society (JAS) guidelines for the diagnosis and prevention of atherosclerotic cardiovascular diseases in Japan—2012 version. J Atheroscler Thromb. 2013;20(6):517-23.

12. Bruckert E, Hayem G, Dejager S, Yau C, Bégaud B. Mild to moderate muscular symptoms with high-dosage statin therapy in hyperlipidemic patients: the PRIMO study. Cardiovasc Drugs Ther. 2005;19(6):403-14.

13. Mampuya WM, Frid D, Rocco M, Huang J, Brennan DM, Hazen SL, Cho L. Treatment strategies in patients with statin intolerance: the Cleveland Clinic experience. Am Heart J. 2013;166(3):597-603. doi:10.1016/j.ahj.2013.06.004. Epub 2013 Aug 5.

14. Moher D, Liberati A, Tetzlaff J, Altman DG, PRISMA Group. Preferred reporting items for systematic reviews and meta-analyses: the PRISMA statement. PLoS Med. 2009;6(7):e1000097.

15. Austrian Lipid Consensus. Management of dyslipidemia in the prevention of vascular complications. Joint Consensus Statement of Austrian eight professional societies. 2010. http://www.oedg.org/pdf/Lipidkonsensus_2010. pdf (20 May 2014, date last accessed).

16. Huber K, Saely CH, Drexel H, Francesconi M, Gaul G, Glehr R, et al. Practical implementation of the guidelines for LDL-lowering. J Cardiol. 2011;18(3-4):96-9.

17. Hankey GJ, Wong KSL, Chankrachang S, Chen C, Crimmins D, Frayne J, et al. Management of cholesterol to reduce the burden of stroke in Asia: consensus statement. Int J Stroke. 2010;5:209-16.

18. Rodondi N, Gencer B, Collet TH, Battegay E. Ab welchem Cholesterinwert soll in der Schweiz eine Behandlung erfolgen? Schweiz Med Forum. 2011;11(27):467-72.

19. Grundy SM, Cleeman Jl, Merz CNB, Brewer HB, Clark LT, Hunninghake DB, for the Coordinating Committee of the National Cholesterol Education Program. Implications of recent clinical trials for the National Cholesterol Education Program Adult Treatment Panel III Guidelines. Circulation. 2004;110:227-39.

20. Reiner Z, Catapano AL, Backer GD, Graham I, Taskinen MR, Wiklund O. ESC/EAS guidelines for the management of dyslipidaemias. The Task Force for the management of dyslipidaemias of the European Society of Cardiology (ESC) and the European Atherosclerosis Society (EAS). Eur Heart J. 2011;32:1769-818.

21. Butler N. National guidelines at a glance: hypercholesterolaemia. Prof Nursing Today. 2010;14(5):26-31.

22. Gami A. Secondary prevention of ischaemic cardiac events. Clin Evid. 2006; 15:195-228.

23. Anderson TJ, Gregoire J, Hegele RA, Couture P, Mancini GBJ, McPherson R, et al. 2012 update of the Canadian Cardiovascular Society guidelines for the diagnosis and treatment of dyslipidemia for the prevention of cardiovascular disease in the adult. Can J Cardiol. 2013;29:151-67.

24. Chung EE. Best practice guidelines for treatment of hypercholesterolaemia: a statement from the Caribbean Cardiac Society. West Indian Med J. 2008;:57(1):48-53
25. Ilerigelen B, Uresin Y, San M, Kültürsay H, Güneri S, Serdar OA, et al. Efficacy and safety of extended-release fluvastatin in Turkish patients with hypercholesterolaemia: TULIPS (Turkish Lipid Study). Curr Med Res Opin. 2007:23(5):1093-102.

26. Maki KC, Davidson MH, Dicklin MR. A comparison of Canadian and American guidelines for lipid management using data from the National Cholesterol Education Program Evaluation Project Utilizing Novel Etechnology (NEPTUNE) II Survey. Can J Cardiol. 2006;22(4):315-22.

27. Bourgault C, Davignon J, Fodor G, Gagné C, Gaudet D, Genest J, et al. Statin therapy in Canadian patients with hypercholesterolemia: the Canadian Lipid Study—Observational (CALIPSO). Can J Cardiol. 2005;21(13):1187-93.

28. Farahani P, Levine M, Gaebel K, LeLorier J, Perrault S, Gillis J, et al. Exploring patient demographic and clinical characteristics associated with lipid-lowering pharmacotherapy use in primary care. Clin Invest Med. 2007;30(2):E63-9.

29. Arafah M, Al-Hinai AT, Mahmeed WA, Al-Rasadi K, Al Tamimi O, Al Herz S, et al. Centralized pan-Middle East Survey on the undertreatment of hypercholesterolemia: results from the CEPHEUS study in Arabian Gulf countries. Angiology. 2014;65(10):919-26. doi:10.1177/0003319713512414. Epub 2013 Dec 3.

30. Vacanti LJ, Santos SC, Fujita AM, Lima DS, Lopes AF, Vetorazi R, et al. Low rate of achieving LDL-cholesterol objective in a low income population. Ara Bras Cardiol. 2005;85(3):162-5.

31. Paragh G, Mark L, Zamolyi K, Pados G, Ofner P. Lipid-modifying therapy and attainment of cholesterol goals in Hungary: the return on expenditure achieved for lipid therapy (REALTTY) study. Clin Drug Investig. 2007;27(9):647-60.

32. Raal F, Schamroth C, Patel J, Becker P. A multicentre, open-label, observational local study to evaluate the low-density lipoprotein cholesterol-lowering effect of ezetimibe as prescribed in daily routine practice in the South African population. Cardiovasc J Afr. 2007;18(5):325-9.

33. Michel G, Muller P. Pan-European survey on the undertreatment of hypercholesterolemia in hypolipidemias (Luxembourg). Bull Soc Sci Med Grand Duche Luxemb. 2008;4:509-16.

34. Assmann G, Benecke H, Neiss A, Cullen P, Schulte H, Bestehorn K. Gap between guidelines and practice: attainment of treatment targets in patients with primary hypercholesterolemia starting statin therapy. Results of the 4E-Registry (Efficacy Calculation and Measurement of Cardiovascular and Cerebrovascular Events Including Physicians' Experience and Evaluation). Eur J Cardiovasc Prev Rehabil. 2006;13(5):776-83.

35. Munawar M, Hartono B, Rifai S. LDL cholesterol goal attainment in hypercholesterolemia: CEPHEUS Indonesian survey. Acta Cardiologica Sinica. 2013;29(1):71-81.

36. Chan RH, Chan PH, Chan KK, Lam SCC, Hai JJ, Wong MKL, et al. The CEPHEUS Pan-Asian survey: high low-density lipoprotein cholesterol goal attainment rate among hypercholesterolaemic patients undergoing lipidlowering treatment in a Hong Kong regional centre. Hong Kong Med J. 2012;18(5):395-406

37. Waters DD, Brotons C, Chiang CW, Ferrières J, Foody J, Jukema JW, et al. Lipid treatment assessment project 2: a multinational survey to evaluate the proportion of patients achieving low-density lipoprotein cholesterol goals. Circulation. 2009;120(1):28-34.

38. Egan BM, Li J, Qanungo S, Wolfman TE. Blood pressure and cholesterol control in hypertensive hypercholesterolemic patients: national health and nutrition examination surveys 1988-2010. Circulation. 2013;128(1):29-41.

39. Wang KF, Chang CC, Wang KL, Wu CH, Chen LC, Lu TM, et al. Determinants of low-density lipoprotein cholesterol goal attainment: insights from the CEPHEUS Pan-Asian Survey. J Chin Med Assoc. 2014;77(2):61-7.

40. Yiginer O, Ozmen N, Ozcelik F, Inanç T, Kardeşoğlu E, Uz O, et al. Adherence to statin therapy and LDL cholesterol goal attainment in type 2 diabetics and secondary prevention patients: the role of education and knowledge. Turk Kardiyol Dern Ars. 2010;38(8):544-50.

41. Foley KA, Denke MA, Kamal-Bahl S, Simpson Jr R, Berra K, Sajjan S, et al. The impact of physician attitudes and beliefs on treatment decisions: lipid therapy in high-risk patients. Med Care. 2006;44(5):421-8.

42. Vijan S, Hayward RA. Pharmacologic lipid-lowering therapy in type 2 diabetes mellitus: background paper for the American College of Physicians. Ann Intern Med. 2004;140(8):650-8.

43. Gomez-Belda A, Rodilla E, Gonzalez C, Costa JA, Serra B, Pascual JM. Lipid lowering goals in high risk and very high cardiovascular risk patients: a reasonable challenge? Rev Clin Esp. 2006;206(9):417-21.

44. Persell SD, Lloyd-Jones DM, Baker DW. Implications of changing national cholesterol education program goals for the treatment and control of hypercholesterolemia. J Gen Intern Med. 2006;21 (2):171-6. 
45. Wong ND, Chuang J, Wong K, Pham A, Neff D, Marrett E. Residual dyslipidemia among United States adults treated with lipid modifying therapy (data from National Health and Nutrition Examination Survey 2009-2010). Am J Cardiol. 2013:112(3):373-9.

46. Nitiyanant W, Sritara P, Deerochanawong C, Ngarmukos P, Koanantakul B. Lipid treatment assessment project II in Thailand (LTAP-II Thailand). J Med Assoc Thai. 2008;91(6):836-45.

47. Iglseder B, Moroder T, Staffen W, Ladurner G. High prevalence and undertreatment of hypercholesterolaemia in participants in a public stroke prevention programme in Austria. Clin Drug Investig. 2005;25(11):709-17.

48. Gajdos M, Krivosikova Z, Uhliar R. A critical gap between recommended and achieved LDL-cholesterol levels. Results of statin therapy in Slovakia. Bratisl Lek Listy. 2007;108(9):388-92.

49. Upadhyay UD, Waddell EN, Young S, Kerker BD, Berger M, Matte T, et al. Prevalence, awareness, treatment, and control of high LDL cholesterol in New York City, 2004. Prev Chronic Dis. 2010;7(3):A61.

50. Flack JM, Victor R, Watson K, Ferdinand KC, Saunders E, Tarasenko L, et al. Improved attainment of blood pressure and cholesterol goals using singlepill amlodipine/atorvastatin in African Americans: the CAPABLE trial. Mayo Clin Proc. 2008;83(1):35-45.

51. Blank R, LaSalle J, Reeves R, Maroni J, Tarasenko L, Sun F. Single-pill therapy in the treatment of concomitant hypertension and dyslipidemia (the amlodipine/ atorvastatin Gemini study). J Clin Hypertens (Greenwich). 2005;7(5):264-73.

52. Wang YR, Alexander GC, Meltzer DO. Screening and treatment of hypercholesterolemia for prevention of coronary heart disease. Manag Care Interface. 2006;19(1):25-9.

53. Davidson MH, Maki KC, Pearson TA, Pasternak RC, Deedwania PC, McKenney $\mathrm{JM}$, et al. Results of the National Cholesterol Education (NCEP) Program Evaluation Project Utilizing Novel E-Technology (NEPTUNE) II survey and implications for treatment under the recent NCEP Writing Group recommendations. Am J Cardiol. 2005;96(4):556-63.

\section{Submit your next manuscript to BioMed Central and we will help you at every step:}

- We accept pre-submission inquiries

- Our selector tool helps you to find the most relevant journal

- We provide round the clock customer support

- Convenient online submission

- Thorough peer review

- Inclusion in PubMed and all major indexing services

- Maximum visibility for your research

Submit your manuscript at www.biomedcentral.com/submit 